\title{
A laboratory study to evaluate the possibility of sulphur and phosphorous removal from iron ore concentrate by leaching
}

\author{
Hassan Rezvani Pour ${ }^{1, a}$, Ali Mostafavi ${ }^{1}$, Tayebeh Shams Pour ${ }^{1}$, Ghobad Ebadi Pour ${ }^{2}$, and Amir Haji \\ Zadeh Omran ${ }^{2}$ \\ ${ }_{1}^{1}$ Shahid Bahonar University, Department of chemistry, Kerman, Iran \\ ${ }^{2}$ Gole-gohar iron ore complex, Sirjan, Iran
}

\begin{abstract}
Iron ore concentrates with high grade sulfur cause several problems in the steel making process, and hence affect the concentrate price. Environmental issues such as sulfur dioxide emission during the concentrate pelletizing process and effect on the steel quality are other issues. The current study was focused on removal of sulfur from the iron ore concentrate by using the chemical leaching technique. The magnetite iron ore concentrate was chosen for this purpose. The results obtained showed that more than $90 \%$ of the total sulfur content was removed from the iron ore concentrate by chemical leaching. Effects of several parameters such as temperature, particle size and use of organic solvent on sulfur removal were investigated by a series of experiments. After optimizing the experimental conditions, it was demonstrated that with addition of sulfur, phosphorus, another important impurity was also removed from the iron ore concentrate. In addition, one of the major advantages of our proposed method was transformation of mineral pyrites to useful by-products such as elemental sulfur.
\end{abstract}

${ }^{\text {a }}$ Corresponding author: rezvani.ch@gmail.com 